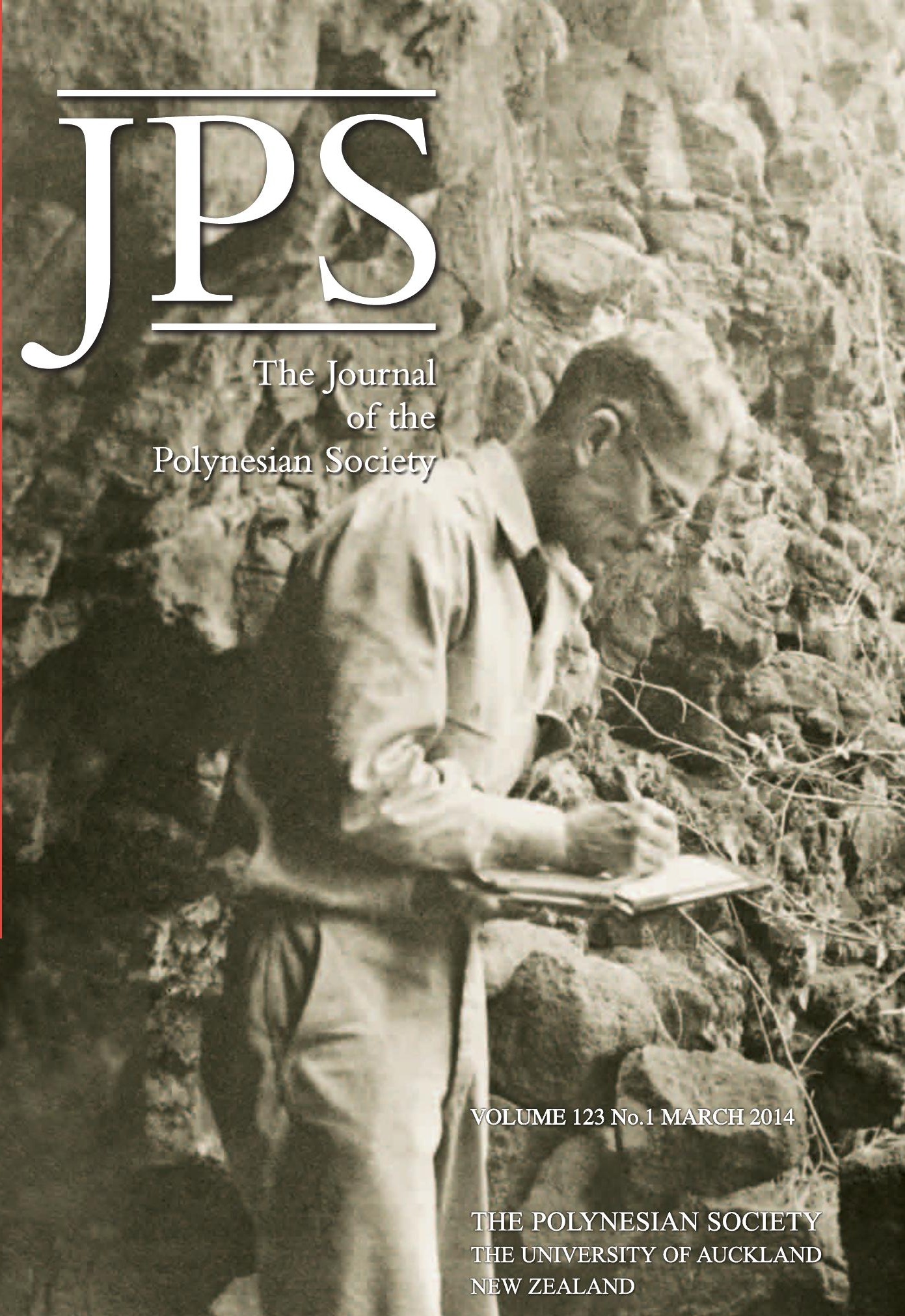




\title{
WIND TUNNEL MEASUREMENTS OF THE PERFORMANCE OF CANOE SAILS FROM OCEANIA
}

\author{
ANNE DI PIAZZA \\ Aix-Marseille Université, \\ Centre National de la Recherche Scientifique (CNRS) \\ Ecole des Hautes Etudes en Sciences Sociales (EHESS) \\ Centre de recherche et de Documentation sur l'Océanie (CREDO) \\ ERIK PEARTHREE \\ FRANÇOIS PAILLÉ \\ Ecole Nationale Supérieure de Mécanique et d'Aérotechnique
}

"Traditional" approaches to canoes and voyaging in the Pacific consist mainly of recording seafaring techniques (Gladwin 1970, Lewis 1972, Thomas 1987), documenting canoe building (Damon 2000, George 1998, Tilley 2002), experimental reconstruction and/or sailing in the few remaining traditional canoes (Finney 2003, Lewis 1972, Thomas 1987), measuring canoe performance at sea (Doran 1972, Finney 1977), and in computer simulations (Avis, Montenegro and Weaver 2008; Di Piazza, Di Piazza and Pearthree 2007; Evans 2008; Irwin, Bickler and Quirke 1990; Levison, Ward and Webb 1973). Another tack consists of predicting hydrodynamics of vessels or aerodynamics of sails in towing tanks, wind tunnels or with computational flow models. To the knowledge of the authors only one such study, on the Marianas flying proa, has been published to date for the Pacific (Jackson and Bailey 1999), although in a recent paper, Irwin (2008) discussed the utility of such an approach.

Important early wind tunnel experiments were conducted by Czeslaw A. Marchaj, National Finn sailing champion in Poland, Research Fellow in the Department of Aeronautics and Astronautics at Southampton University, and later an independent aerodynamics consultant. His publications such as "Sailing Theory and Practice" written in the mid 1960's, followed by "AeroHydrodynamics of Sailing" (1988), "Seaworthiness: The Forgotten Factor" (1986) and "Sail Performance: Techniques to Maximise Sail Power" (2010), have become classic references. His involvement in many different research projects, such as rig design for a 12-metre America's Cup challenger, and development of sail rigs for Third World fishing fleets, also led him to study the Polynesian "crab claw" rig. During his long career, one of the important hypotheses he developed is that "the practically extinct crab claw type of sail -once used by the Polynesian seafarers - is superior to the fiercely guarded product of racing and rating rules", namely the triangular Bermudan sail (Marchaj 2003: 161). 
But what does Marchaj mean by "crab claw" rig? No detailed description of the rig is given except that "crab claw rigs were characteristic of western Polynesia when Tasman and Schouten were exploring in the Tonga area in the 17th century" (Marchaj 2003: 160, Fig. 143). Referring to his figures (Marchaj 2003: 175, Figs 133, 139, 141, 142, 146, 148, 160), his "crab claw" rig can be defined as an "axisymmetric" triangular sail, with a deep bay or hollow in the head, spread between two spars slightly curved in plan, fixed to a vertical mast. This sail, while not replicating any particular Oceanic rig, does have similarities with the axisymmetric sails used in Fiji and Tonga, although there it is slung from a pivoting forward leaning mast (contra the fixed vertical mast in Marchaj), its tack is fixed to the prow (this detail is unclear in Marchaj's figures), and it seems to have had a more pronounced camber. ${ }^{1}$ Marchaj's objective was not so much to copy actual Oceanic sails, but to test "basic rigs" (Marchaj 2003: 153).

The primary objectives of this paper are twofold: (i) to test different traditional Pacific rigs in a wind tunnel, rank their relative performance, and compare these results with other studies, in particular Marchaj's "crab claw"; and (ii) to question developmental implications of such results and consider whether the geographic distribution of the various rigs could shed some light on the history of settlement within Oceania.

Such experiments should prove helpful when attempting to better comprehend the maritime world faced by prehistoric sailors. Indeed, even though Pacific seafaring has captured the attention of scholars for centuries, debates continue about the performance of ancient canoes (Anderson 2000, 2001; Finney 2006; Irwin 2008; Levison et al. 1973), the extent of maritime knowledge (Irwin 1992), the architectural traits and rigs of vessels of the past (Anderson 2000, 2001; Doran 1981; Horridge 1987, 2008) and the evolutionary processes that shaped them (Beheim and Bell 2011, Doran 1981, Haddon and Hornell 1975, Horridge 1987, Irwin 2008, Neyret 1974, Rogers and Ehrlich 2008). We advocate here that the physics of aerodynamics (and eventually hydrodynamics) should help to , better understand the technological capacities and constraints on sailing canoes in relation to their history, environment and distribution.

\section{PACIFIC RIGS TESTED}

We chose ten rigs (some of which are no longer used, some are still in use) with different types of sail geometry to represent the diversity across the Pacific, from the Philippines to Eastern Polynesia. These rigs used two distinct means of coming about: shunting and tacking. Shunting canoes (Ninigo, Massim, Arawe, Micronesia, Tonga, Santa Cruz and Vanuatu) always keep the outrigger, and thus one side of the hull, to windward. The bow becomes the 
stern and vice versa. Their hulls are symmetrical fore and aft, and sometimes asymmetrical windward to leeward with fuller forms to windward. Tacking canoes (Vanuatu, Tonga, Tahiti, Hawaii, Marquesas) have dedicated bows and sterns and their outriggers will thus be alternatively on the windward and leeward side. ${ }^{2}$ Their hulls are symmetrical port and starboard.

Drawings of the ten sail types are shown in Figure 1. Traditional sails are still used in scattered locations in Oceania, although nowadays they are generally rendered in canvas (or even rice sacks) instead of traditional pandanus mats. ${ }^{3}$
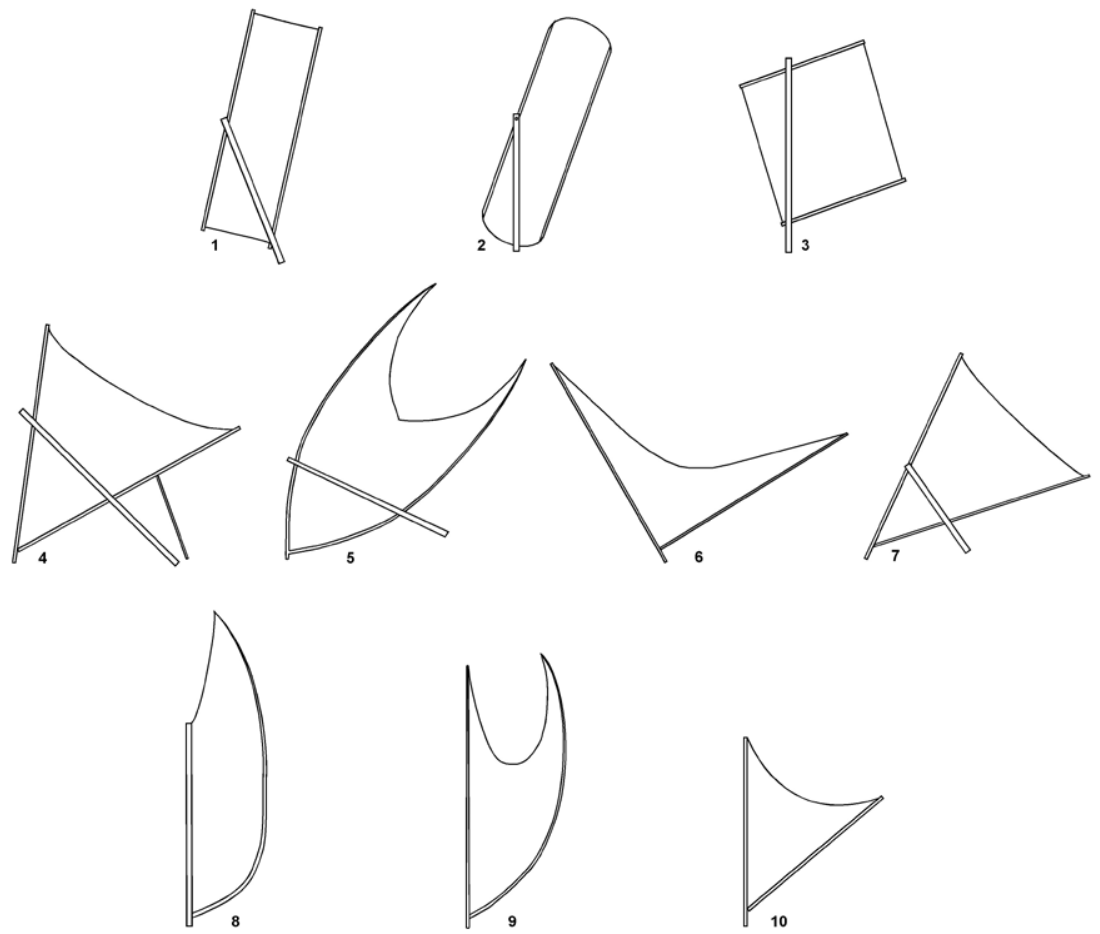

Figure 1. Drawings of the different model sails. 1. Ninigo, 2. Massim, 3. Arawe, 4. Micronesia, 5. Santa Cruz, 6. Vanuatu, 7. Tonga, 8. Tahiti; 9. Hawaii, 10. Marquesas. Sails 1, 2 and 3 are Oceanic lugsails; 4, 5 and 7 are Oceanic lateens; 6, 8, 9 and 10 are Oceanic spritsails. 
Where sails have disappeared, our best sources are the drawings of early voyagers, especially those of Admiral Pâris who gave the most detailed measured plans of canoes ever made. Many of them have been re-published by Rieth (1993). Captain Cook, some of his officers, notably Bligh, and the various artists who accompanied him on his three voyages, especially Parkinson, Hodges and Webber, made numerous drawings and sketches of now vanished canoe types. Haddon and Hornell (1975) and Dodd (1972) made important contributions towards Pacific canoe typology and understanding of their historical evolution. Their books are the most complete compilations of images of Pacific canoes, and include those of Pâris' and Cook's artists.

For clarity, we refer to the different sail types by the name of the island or archipelago where they were recorded. Their order of presentation is roughly from West to East, regrouped into three rig types: Oceanic lugsails, Oceanic lateens and Oceanic spritsails. The dimensions of our sails and spars were taken either from scaled drawings (Micronesia, Tonga, Santa Cruz), sketches or photographs illustrating the sail at right angles. Human figures (assumed to be $1.7 \mathrm{~m}$ tall) were used for scale.

Ninigo is the boomed lugsail still used on shunting single outrigger canoes in the Ninigo Islands (Western Bismarck archipelago) of Papua New Guinea. The rectangular sail is lashed between the yard and the boom, which ends in a fork stepped upon the lower end of the mast. The mast is socketed on the leeward gunwale and is pivoted toward the bow during the shunting manoeuvre like an Oceanic lateen. Our example is based on the sails from Haddon and Hornell (1975 [2]: 176, Fig. 108) and Lewis (1972: 267, Plate XII).

Massim is the unusual rig of the shunting ${ }^{4}$ outrigger canoe nagega (anageg after Damon 2000) still in use in the eastern part of the Kula Ring area, notably on Gawa and Murua Islands in the Milne Bay Province, New Guinea (Malinowski 1961, Munn 1977, Damon pers. comm. 2010). The rig has been described as "flattened oval" or "rounded oblong" in Haddon and Hornell (1975 [2]: 279-81, 1975 [3]: 53) and as "tilted elliptical" by Horridge (1987, Fig. 83, type p). Our model rig is based on a photograph (Haddon and Hornell 1975 [2]: Fig. 150), with the length to width ratio calculated at $1: 4$ to correct for picture distortion. Perhaps the clearest image of this sail is from Irwin (1999, Fig. 14.2).

Arawe is the boomed lugsail used on fixed vertical masts on shunting single outrigger canoes in scattered locations around the Bismarck Archipelago, north of New Guinea. Our example is based on a photograph by Speiser from the Arawe Islands, off the southwest coast of New Britain, published in Haddon and Hornell (1975 [2]: 162, Fig. 98). Whether these sails are still in use is unknown to the authors. 
Santa Cruz is a type of shunting Oceanic lateen sail with a very deep hollow in the head. This distinctive rig is restricted to the Santa Cruz group at the south end of the Solomon Islands. Today, reconstructed Te Puke (Tepuke) canoes with this rig are again sailing in the Solomon waters. ${ }^{5}$ Photographs and drawings used for our model sail come from the Templeton Crocker Expedition of 1933, as published in Haddon and Hornell (1975 [2], Fig. 33) and from Pâris ([1843], Plate 114).

Micronesia is a shunting Oceanic lateen sail used on outriggers throughout the Marianas, the Carolines, Kiribati and the Marshalls. Our sail is based on an example from Puluwat Atoll, in the Caroline Archipelago, measured by Doran (1981: 30, Fig. 10). This sail has a wide tack angle (the angle between the yard and the boom) and the yard is normally rigged nearly vertical, although it may be adjusted lower.

Tonga refers to the Oceanic lateen sails used on large double or outrigger voyaging canoes in Tonga, Fiji and other nearby islands. This rig differs from Micronesia in that the tack angle is always narrower and its yard lower. It was still in use in the mid-19th century in Tonga. This rig is still sailing on several of the southern Lau Islands in Fiji (Gillett 1993). Although most canoes with this rig used the shunting manoeuvre, one type, the Tongiaki, had the particularity of coming about by tacking (Thomson 1908: 295). The best illustration of the rig of a Tongiaki is from Hodges (Dodd 1972: 77; Haddon and Hornell 1975 [1], Fig. 192).

Vanuatu is a variant of the Oceanic spritsail, known as the butterfly sail. It is used with both tacking and shunting manoeuvres. It is characterised by two long edges supported by straight spars, a wide tack angle (about $90^{\circ}$ ) and a deep symmetrical curve of the head. This rig, once used in the central and northern islands of Vanuatu, disappeared in the early 1900s. Height, width and curvature ratio come from photographs by Speiser (1996: Plate 62.7) and McCulloch (Haddon and Hornell 1975 [2]: 30, Fig. 18).

Tahiti is a type of Oceanic spritsail, with a characteristic head supported by a sprit and extending above the mast head. It was once used on both double and outrigger canoes. This rig disappeared about 200 years ago. Our measurements are based on drawings made by early explorers to Tahiti, especially a sketch by Parkinson (Dodd 1972: 127), as well as drawings by Webber and Hodges (Dodd 1972: 130, 131, 139). The canoe sail from Tahiti discovered at the British Museum, with a width to height ratio of 1:6, has recently improved our understanding of this sail (Hiquily et al. 2009).

Hawaii is a type of Oceanic spritsail spread between a vertical mast and a curved sprit, with a very deep curve in-between, somewhat resembling the Santa Cruz and Vanuatu rigs. No longer in use, it is poorly documented. The best field sketch we found to replicate the sail was drawn by Webber (Dodd 1972: 116). 
Marquesas is a type of Oceanic spritsail spread between two straight or nearly straight spars, fallen into disuse today. Our sail is based on a drawing by Hodges which, according to Haddon and Hornell, is the only record of an ancient Marquesan sail (Haddon and Hornell 1975 [1]: 35, see also Dodd 1972: 132-33).

\section{MAKING THE SAILS}

Our rigid experimental sails were made out of laminated epoxy-fibreglass with the outer surface left rough to reflect the traditional ones of plaited Pandanus tectorius mats, as well as to insure a fully turbulent flow regime. Surface roughness and wind velocity are important factors to promote the transition from laminar to turbulent flow in order to make certain that model results are comparable to full scale sails (Schlichting 1979).

While data is available for rig geometries and sail planform (sail shape when viewed from side), details of their airfoils are unknown. Rather than attempting to study differences in airfoils, all sails were laid-up on the same male mould with maximum camber at mid-chord and flattened sections fore and aft. Marchaj has shown that cambers between 1:7 and 1:10 at mid chord are "the best all-round compromise" for the different points of sail, although somewhat too full for maximum efficiency sailing to windward in strong winds (Marchaj 1964: 129-133, 138). In any case fragile mat sails would

Table 1. Geometrical characteristics of the different rigs. Sail surfaces of reference (S) were calculated in $\mathrm{m}^{2}$ from digital photographs of the models.

\begin{tabular}{|lclcc|}
\hline & $\begin{array}{c}\text { Height }(\mathrm{H}) \\
(\mathrm{m})\end{array}$ & $\begin{array}{c}\mathrm{S} \\
\left(\mathrm{m}^{2}\right)\end{array}$ & $\begin{array}{c}\text { Aspect ratio } \\
\left(\mathrm{H}^{2} / \mathrm{S}\right)\end{array}$ & Camber \\
\hline Ninigo & 0.31 & 0.03026 & 3.17 & $1: 11$ \\
Massim & 0.29 & 0.0267 & 3.15 & $1: 10$ \\
Arawe & 0.27 & 0.0424 & 1.72 & $1: 11$ \\
Micronesia & 0.31 & 0.04431 & 2.17 & $1: 10$ \\
Santa Cruz & 0.39 & 0.0383 & 3.97 & $1: 10$ \\
Vanuatu & 0.29 & 0.01939 & 4.34 & $1: 10$ \\
Tonga & 0.25 & 0.03355 & 1.86 & $1: 10$ \\
Tahiti & 0.44 & 0.03298 & 5.87 & $1: 7$ \\
Hawaii & 0.38 & 0.0273 & 5.29 & $1: 10$ \\
Marquesas & 0.26 & 0.01498 & 4.51 & $1: 11$ \\
\hline
\end{tabular}


generally be taken down in these conditions. Giving all our sails the same airfoil facilitates comparison, although being rigid they cannot reflect all the complexity of real sails which stretch, twist and change camber depending on heading and sail adjustment.

Masts were made from 4-8 $\mathrm{mm}$ diameter carbon fiber tubing. Yards, booms and sprits were constructed using $3 \mathrm{~mm}$ diameter carbon rod, bamboo (Tahiti, Santa Cruz) or wood (Massim, Hawaii). Spritsails were fixed to the axis of the mast. Yards, sprits or booms were fixed on the windward side of the sail. Additional geometrical characteristics of the tested sails are show in Table 1.

\section{METHODS OF MEASURING THE AERODYNAMIC FORCE IN A WIND TUNNEL}

In a wind tunnel, a fan blows air over a static model sail mounted on a sensitive balance which measures aerodynamic forces (lift, drag, pitch) generated by airflow over the sail. The magnitude of these forces depends on wind speed, sail area, angle of incidence, sail geometry (camber, aspect ratio) and characteristics of the sail surface (porosity, roughness, etc.) (Marchaj 2003: 79).

Tests were carried out in the subsonic wind tunnel named "Bois" at the "Ecole Nationale Supérieure de Mécanique et d'Aérodynamique" in Poitiers, France. It has an open circuit with an octagonal test-section $\left(1 \mathrm{~m}^{2}\right)$, producing a uniform flow to a maximum speed of $80 \mathrm{~m} / \mathrm{s}$ (meters per second), with a turbulence level less than $0.3 \%$ at $40 \mathrm{~m} / \mathrm{s}$. To avoid wall interference effects, the model sails were less than $50 \mathrm{~cm}$ high.

The sails were mounted on a turntable connected to a balance which measures the force on six axes. Here we are mainly concerned with the drag force (D), parallel to the wind direction and the lift force (L), perpendicular to the wind direction (Fig. 2). Sails were initially adjusted parallel to the wind (angle of incidence $(\alpha)$ of $0^{\circ}$ ). The turntable is rotated from $0^{\circ}$ to $80^{\circ}$ (by $2^{\circ}$ steps) and then back to $0^{\circ}$, so as to verify the first results. Greater incidences are generally not used by sailing canoes. Oceanic lateens cannot sail directly downwind because the rig is held up by wind force. It has no stays on the leeward side and will fall overboard or capsize the canoe if the sail is caught aback, that is when the wind pushes the sail against the mast. Oceanic spritsails could sail safely almost directly downwind with their sails turned forward of the mast, as can be seen in the numerous illustrations from Hawaii and Tahiti by Cook's artists. 


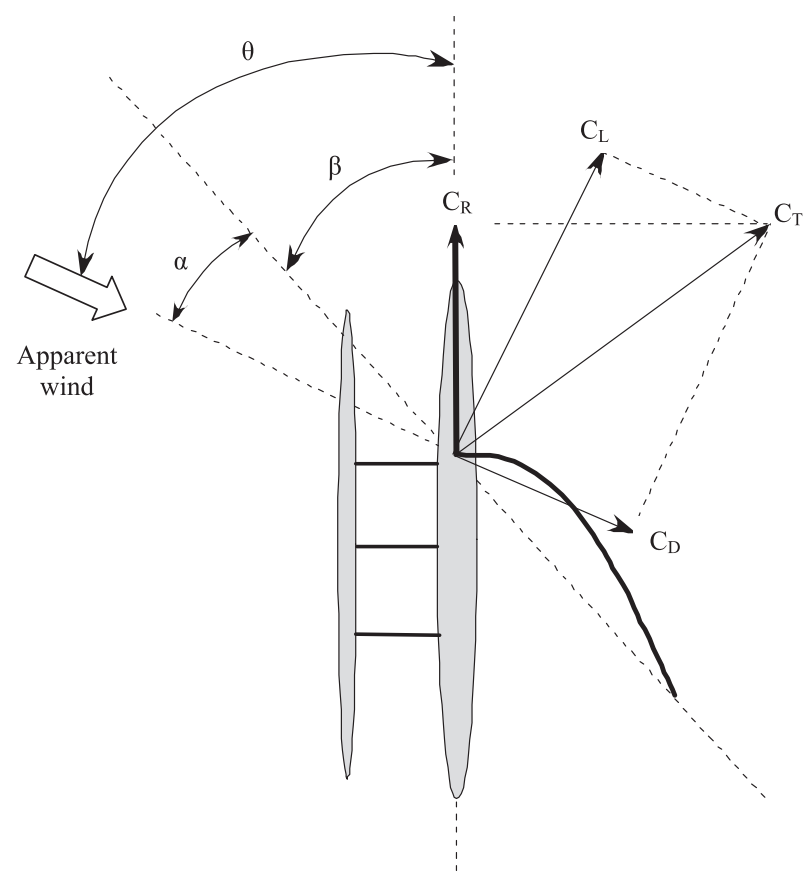

Figure 2. The coefficients and angles used in these experiments and discussed in the text.

$\mathrm{C}_{\mathrm{L}}$ is the lift ( $\left.\mathrm{L}\right)$ coefficient.

$\mathrm{C}_{\mathrm{D}}$ is the drag (D) coefficient.

$\mathrm{C}_{\mathrm{T}}$ is the resultant of both $\mathrm{C}_{\mathrm{L}}$ and $\mathrm{C}_{\mathrm{D}}$.

$\mathrm{C}_{\mathrm{R}}$ is the driving force coefficient that is $\mathrm{C}_{\mathrm{T}}$ projected onto the heading.

$\alpha$ is the incidence of the sail relative to the apparent wind.

$\beta$ is the angle which represents the trim of the sail relative to the heading.

$\theta$ is the angle formed by the apparent wind and the heading; it characterises the point of sail.

\section{RESULTS}

In Figure 3 lift and drag measurements obtained from the ten test sails are plotted as coefficients of lift $\left(\mathrm{C}_{\mathrm{L}}=2 \mathrm{~L} /\left(\rho \cdot \mathrm{S} \cdot \mathrm{v}^{2}\right)\right)$ and $\operatorname{drag}\left(\mathrm{C}_{\mathrm{D}}=2 \mathrm{D} /\left(\rho \cdot \mathrm{S}_{\mathrm{V}} \mathrm{v}^{2}\right)\right)$. The measurements are normalised to the surface area of the sail (S). True wind speed is referred to as $\mathrm{v} ; \rho$ is the air density. The curves give the magnitude of the resultant force, varying with incidence for each sail at a given wind speed. A wind speed of $25 \mathrm{~m} / \mathrm{s}$ was chosen so that the measured forces would 
fall in the zone of maximum sensitivity of the balance for all sails, except for Santa Cruz where the test was made at $20 \mathrm{~m} / \mathrm{s}$; this was done because at higher speeds, oscillation of the tips of the sail shook the balance, causing inaccurate measurements. This difference in wind speed has no effect on our unit-less coefficients. It should be noted that in Figure 3, the incidence of $0^{\circ}$ is defined as the point of zero lift or $\mathrm{C}_{\mathrm{L}}=0$.

At low incidences, once the sail fills, its lift begins to increase and the curve climbs steeply. Where the tangent to the curve is nearly vertical, the lift increases much faster than the corresponding drag and the lift/drag ratio is at its greatest. Beyond this point, both lift and drag continue to increase but the $\mathrm{C}_{\mathrm{L}} / \mathrm{C}_{\mathrm{D}}$ ratio decreases. Where the tangent to the curve is $45^{\circ}$, the drag begins to increase faster than the lift. The maximum windward performance of the sail is between these two tangents or points. Lift and drag still continue to increase, up to the stall, the summit of the curve, where lift is at its maximum. Beyond this point the curve descends and drag force becomes increasingly important. At very high incidences (beyond $60^{\circ}$ ), the sail is propelled more by drag than by lift.

In light of Figure 3, it appears that close-hauled (that is when sailing to windward), lift to drag ratio (L/D) is the most important factor. Massim, Ninigo and Tahiti, have the highest L/D and are expected to be the most efficient of the ten sails tested when sailing to windward. With respect to beam reaching (with the wind at $90^{\circ}$ and the sails at their highest $\mathrm{C}_{\mathrm{L}}$ ), Santa Cruz has the best performance of all, although Ninigo and Massim are almost as good. They are followed by Arawe, Micronesia, Vanuatu and Marquesas. The other three sails (Tonga, Hawaii, Tahiti) have the lowest maximum $\mathrm{C}_{\mathrm{L}}$. Broad reaching and running (from about 100 to $160^{\circ}$ off the wind), there is little difference in the performance of all the sails, although again Santa Cruz is the best.

Two classes of stall can be noted, relatively abrupt or gentle. A possible explanation for the abrupt stall of Tahiti and Massim lies in the elongated shape and high aspect ratio of their sails, as well as their nearly vertical leading edges. This makes them behave somewhat like airplane wings with a two-dimensional stall (occurring at nearly the same moment along the height of the sail). For the other sails, with inclined leading edges (Tonga) and/or large changes in geometry along their lengths (such as the deep curves in the heads of Santa $\mathrm{Cruz}$ and Vanuatu sails), the stall is certainly modified by three-dimensional effects, such as vortex lift. Vortex lift works by capturing the vortices generated along the leading edges (yard and boom) of the sail, keeping them attached to the surface and retarding the stall (Marchaj 2003: 161-66).

To further examine the power of these rigs, the coefficient of driving force $\left(C_{R}\right)$ is plotted against the heading of the canoe $(\theta)$ (Figs 2, 4). $C_{R}$ is the resultant of coefficients $C_{L}$ and $C_{D}$ projected onto the course sailed or 

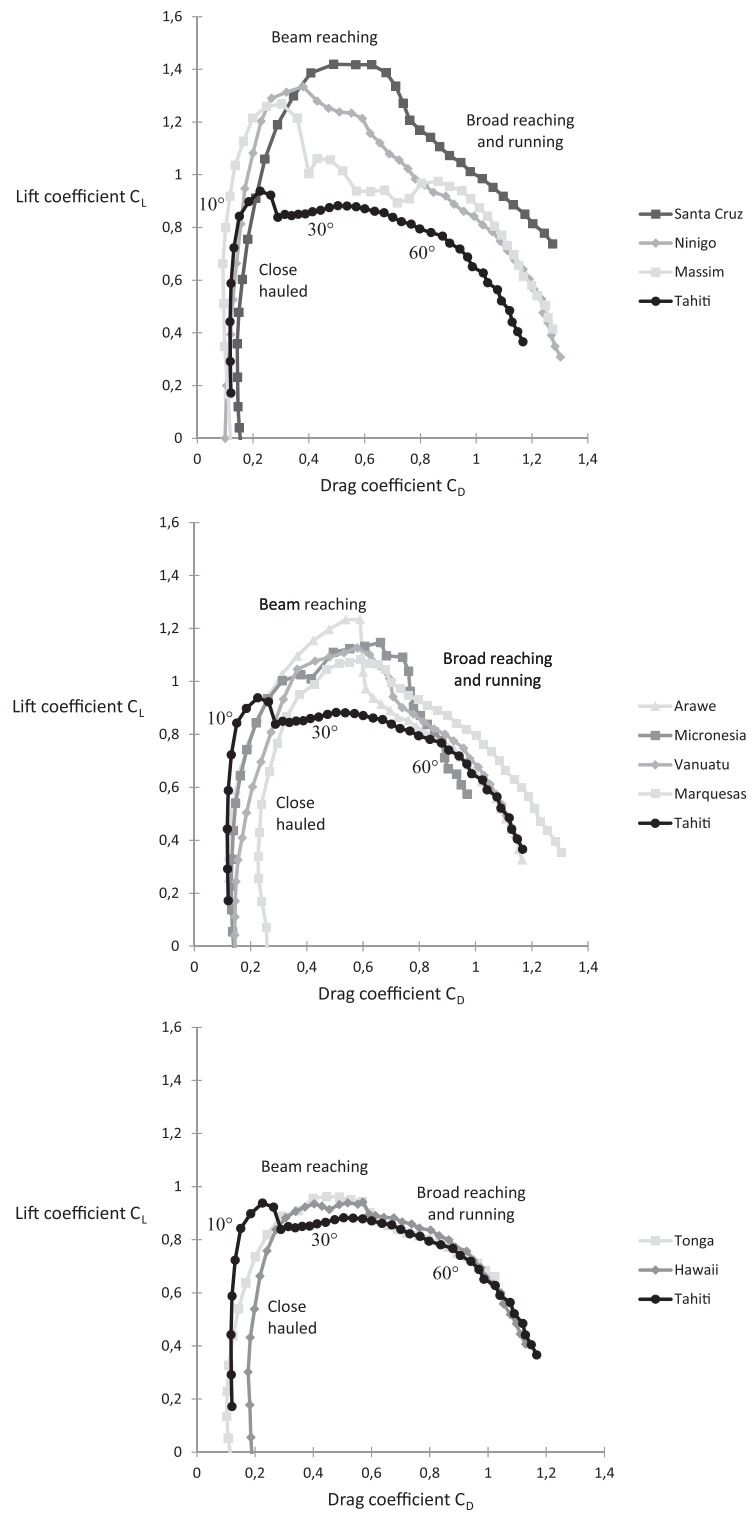

Figure 3. Drag coefficient over lift coefficient. Tahiti has been repeated on the three diagrams to facilitate comparisons. The dots represent $2^{\circ}$ increments of sail incidence. Incidences of 10,30 and $60^{\circ}$ are indicated for Tahiti. 
heading. ${ }^{6}$ To calculate maximum $\mathrm{C}_{\mathrm{R}}\left(\mathrm{C}_{\mathrm{R}}=\left(\mathrm{C}_{\mathrm{D}} \cdot \operatorname{Cos} \beta\right)+\left(\mathrm{C}_{\mathrm{L}} \cdot \operatorname{Sin} \beta\right)\right)$, one has to determine appropriate values of angle $(\beta)$, that is, the trim angle of the sail relative to the heading. The method used in these experiments consisted of calculating $C_{R}$ at $5^{\circ}$ increments of $\beta$ (from 0 to $180^{\circ}$ ) and plotting the best result, which represents a sail adjusted for its highest efficiency.

Not surprisingly, the ranking of the sails at different heading angles against driving force coefficient $\left(\mathrm{C}_{\mathrm{R}}\right)$ in Figure 4 is similar to that obtained with the $\mathrm{C}_{\mathrm{D}}$ over $\mathrm{C}_{\mathrm{L}}$ coefficients (Fig. 3). At low heading angles, from about $30^{\circ}$ to $80^{\circ}$, three sails (Santa Cruz, Ninigo, Massim) are remarkable for their higher efficiency. Four other sails (Arawe, Micronesia, Vanuatu, Marquesas), while somewhat less efficient close hauled, have similar performance throughout almost the entire range of headings. The last three sails (Tonga, Hawaii, Tahiti) also cluster together with lower performance throughout, except for the case of Tahiti when close hauled. Indeed Tahiti appears to be specialised for windward headings. In the light of these observations, it appears that in general, Oceanic lugsails (Ninigo, Massim, Arawe) are more efficient than Oceanic lateens or spritsails and that within these last two groups, there is fairly high variability. However, at heading angles greater than $55^{\circ}$, one Oceanic lateen (Santa Cruz) surpasses them all.

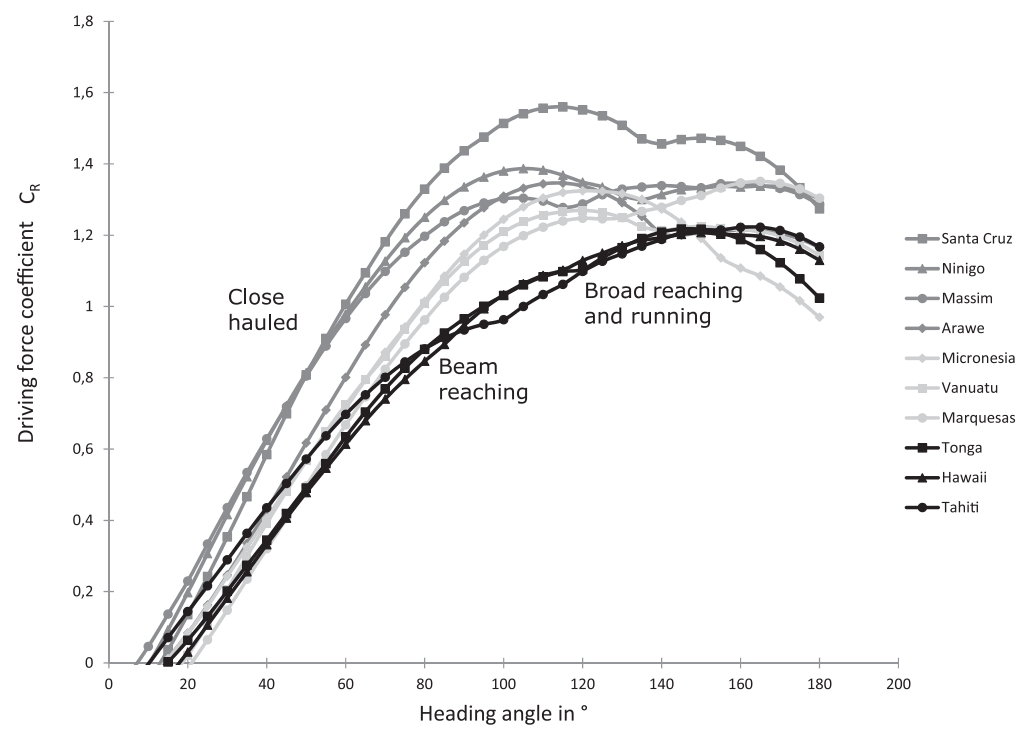

Figure 4. The driving force coefficient $\left(\mathrm{C}_{\mathrm{R}}\right)$ over the heading 
The ranking discussed here is a first attempt at a general comparison of sail efficiency based on lift and drag characteristics. But to derive more complete performance figures, such as canoe velocity relative to wind speed and heading, will require additional studies on the hydrodynamics of canoe hulls and estimation of sail area to canoe displacement. Finney has noted that shunting canoes rigged with the Oceanic lateen should sail significantly faster than spritsail-rigged tacking canoes with their nearly upright leading edges (Finney 2006: 131). Although the wind tunnel tests did not clearly differentiate an Oceanic lateen class versus an Oceanic spritsail class, the general pattern is that lateens are the more efficient. Since the sail area to displacement ratio of spritsails is also much lower than that of lateens, ${ }^{7}$ it is likely that Finney is correct.

\section{DISCUSSION}

The aerodynamics of sails are now well understood for conventional yachts but little work has been done on traditional sailing canoes. The results presented here are thus still somewhat preliminary since there are only two limited comparative studies available: Marchaj's "crab claw" and Jackson and Bailey's Marianas proa. Among our sails, the one that most closely replicates the performance of Marchaj's "crab claw" (2003: 160, Fig. 142) is Santa Cruz (Fig. 5). This raises the question of why the driving forces of Santa Cruz and Marchaj's "crab claw", to which we can add Ninigo and Massim, are substantially higher than the others. Marchaj discussed the following factors as contributing to the efficiency of his "crab claw" sail: leading edge stiffness, relatively flat camber, a planar (untwisted) sail, a rounded nose or tack angle and a moderate sweepback or yard angle (Marchaj 2003: 167-73). For Marchaj, a stiff leading edge produced higher lift. All our model sails had relatively stiff, round leading edges, except Santa Cruz whose thin tipped spars oscillated at high wind speed. As far as camber, Marchaj noted that for his axisymmetrical conical sails, "the less the camber, the higher the lift" (Marchaj 2003: 169). Our sails moulded with the same camber at mid chord did not allow comparison. Marchaj noted that a "crab claw" sail with its tack fixed to the deck, holding the sail planar and untwisted, gave as much as 35\% more driving force than the same sail with its tack left free (Marchaj 2003: 170). All the Oceanic rigs tested here had fixed tacks, effectively eliminating sail twist and improving efficiency. Marchaj found that a rounded tack angle with curved spars (D in Figs 161, 164) was superior. Indeed, our Santa Cruz model was more efficient than the Tonga and Micronesia sails with their straight spars and pointed tacks. Marchaj claimed that for best performance to windward, the sail should be set with a medium sweepback angle (Marchaj 2003: 173, Fig. 162). He used yard angles of $7^{\circ}, 38^{\circ}$ and $69^{\circ}$ aft as measured 


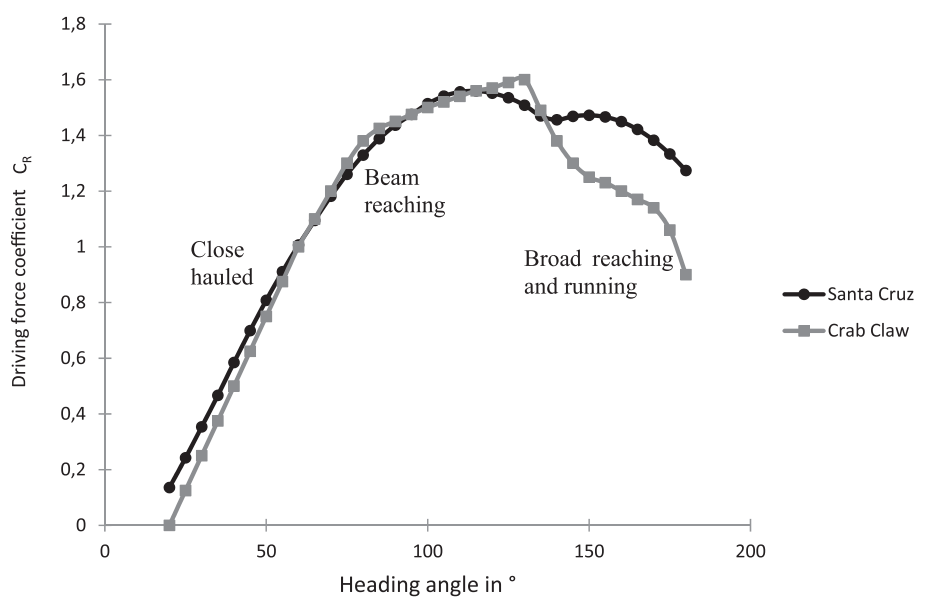

Figure 5. A comparison of driving force coefficients of the Santa Cruz sail and Marchaj’s “crab claw” sail (after Marchaj 2003: 160, Fig. 142).

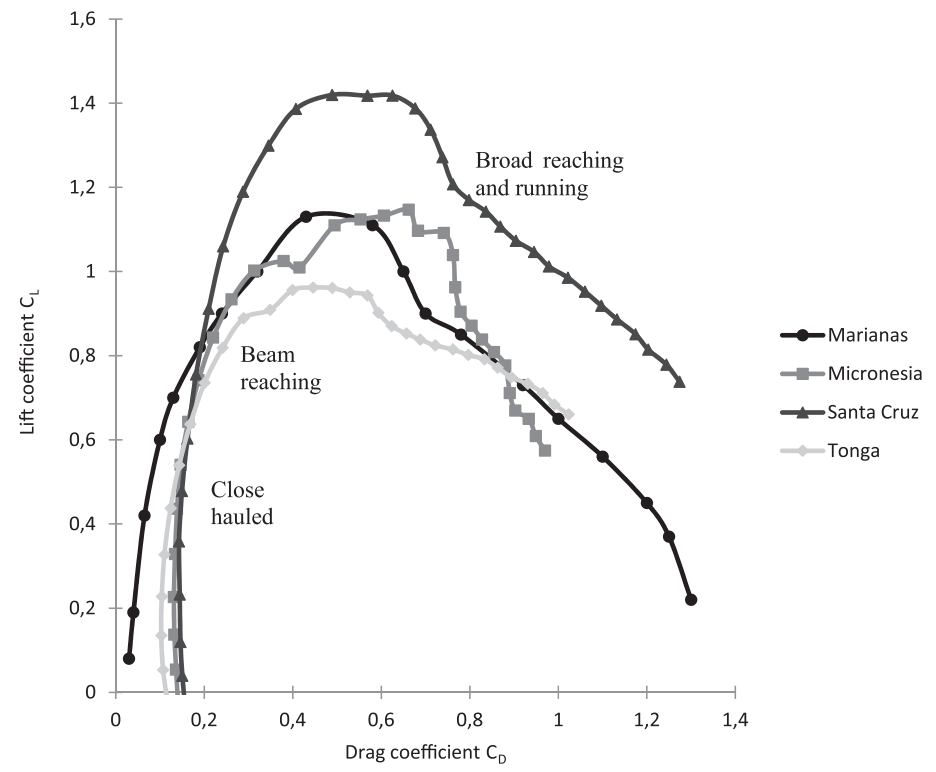

Figure 6. Three Oceanic lateen sails, Micronesia, Tonga and Santa Cruz compared to the Marianas proa (after Jackson and Bailey 1996: Fig. D.4). 
from his Figure 162. Our best data on the effects of variable yard angles are for the Massim Oceanic lugsail. It was more efficient with its yard angle at $10^{\circ}$ and $20^{\circ}$ than at $30^{\circ}, 40^{\circ}, 50^{\circ}$.

The performance of Jackson and Bailey's (1996) Marianas proa rigged with an Oceanic lateen sail is consistent with our three Oceanic lateens. Their maximum values are closest to our Micronesia and the overall shape of their curve to Santa Cruz (Fig. 6). These broader comparisons tend to support our results.

Oceanic sailing canoes have been shaped by hundreds, even thousands of years of experiences and indeed their rig types appear to be correlated with the history of settlement inferred from geographical distribution and historical linguistics. Within the vast area settled by Austronesian sailors, we recognise three regions, each with its distinctive and exclusive rig type. Today, the western region, from Indonesia and the Philippines to northern New Guinea, is inhabited by Western Malayo-Polynesian speakers, whose dominant canoe type is a double outrigger that tacks through the eye of the wind and carries a rectangular Oceanic lugsail. The central region, including Island Melanesia, Western Polynesia and Micronesia, is peopled by Oceanic speakers whose prevailing canoe type is the shunting single outrigger with an Oceanic lateen sail. The last region is Eastern Polynesia, where tacking canoes carry Oceanic spritsails. ${ }^{8}$ While we have no archaeological evidence of the antiquity of any of these types, their distribution correlates with the three major periods of Pacific settlement: the arrival of the Austronesians in the western region perhaps 6,000 years ago, in the central region around 3,500 years ago and in the eastern region some 1,000 years ago. If indeed, these three rig types were used by the Austronesian sailors who discovered and settled each of these three regions, it implies that Oceanic lugsails, lateens and spritsails were all innovated before the settlement of the newly discovered regions. While our model sails, based on relatively recent data can be classed into these three types, we do not think of any of them as representing ancient prototypes, but rather as the outcome of a long history of local innovations and/or borrowings.

There are other models in the literature about Austronesian canoe origins. Among the most recent are those of Horridge (2008) and Irwin (2008). For Horridge (2008: 86) the ancestral rig used for the settlement of Western and central Oceania was "the triangular sail... supported by two-booms, pushed up with a loose prop [mast]" (our shunting lateen rig type). For Irwin, the simple two-spar rig (Oceanic spritsail) is the oldest, predating the three-spar Oceanic lateen. He argues it was the one probably used during the Lapita settlement of the central region some 3,500 years ago (Irwin 2008), as well as for the discovery of East Polynesia some 2,500 years later (Irwin 2011). 
Concerning the central region, linguistic reconstruction of Proto-Oceanic (POC) indicates that canoes were dugouts with sewn on gunwale strakes, single outriggers and sails, although no terms could be reconstructed for either the type of sail or the maneuver (shunting or tacking) (Greenhill and Clark 2011; Pawley and Pawley 1994). The one reconstruction that allows inferences about rig type seems to be reflexes of *jila whose meanings range from boom or yard to mast in different lower order subgroups of Oceanic languages. According to Pawley and Pawley, in POC *jila refers to one of the spars supporting the sail, either the yard or the boom in Admiralty Islands (ADM), in Western Oceanic (WO) and in Central and Northern Vanuatu (CNV). Further east, this term refers to yard in Tonga and Pukapuka, sprit or mast in Samoa, mast or spar in Tikopia, and mast in Tahiti, Mangaia and New Zealand (Pawley and Pawley 1994: 350-51). They further note that "the use of reflexes of *jila to denote a fixed mast is confined to certain parts of Polynesia [Tikopia, Samoa, East Polynesia] and this sense probably represents a post-PPN innovation" (Pawley and Pawley 1994: 351). We believe that the shift in meaning from yard or boom to mast may well reflect a technical innovation from the three spar lateen to the two spar spritsail, where the forward sail spar became a functional mast, somewhere in West Polynesia (Di Piazza in press).

While it is generally agreed that the Oceanic spritsail served for the discovery of East Polynesia, there is divergence in where and when it was innovated. For Horridge, it was after the initial Austronesian expansion. For Irwin, it was prior to the Lapita expansion, therefore more than 3,500 years ago. We argue here that it was during the long pause between the settlement of Samoa and that of East Polynesia.

$$
\text { *** }
$$

For different practical reasons (bans on sailing by colonial administrations, the introduction of canvas, etc.), the weaving of sails has practically ceased in contemporary Pacific societies. To better understand how they perform, we presented data from wind tunnel tests whose results allow ranking of ten Oceanic sails and discussion of differences in relative performance based on empirical data. The analysis brings out some interesting points. Key among these is the relative high efficiency of Oceanic lugsails. The analysis also points to wide variability within the lateen sails, including the surprising high efficiency of the Santa Cruz sail. Finally, it indicates the good all-around performance of the Marquesas spritsail relative to the Hawaii and Tahiti. 


\section{ACKNOWLEDGEMENTS}

We would like to thank Alain Farcy and Jacques Boré for the welcome they gave us at E.N.S.M.A (Ecole Nationale Supérieure de Mécanique et d'Aérodynamique), Institut Pprime, Département Fluides Thermique Combustion - UPR 3346 and their help throughout the wind tunnel experiments. Their comments, discussions and thoughtful reviews during and especially afterwards, while we were beginning to understand the results were crucial. Particular thanks are due to Alain Farcy for patiently responding to our many questions. We would also like to thank Melinda Allen for thoughtful comments on an earlier draft of this paper as well as the two anonymous reviewers whose comments substantially improved our thinking. This study was conducted under framework Apex (Appel à Projets Ouverts, Volet Exploratoire) - Pirocco (Pirogues, Océanie, Corpus), funded by the Direction de l'Economie Régionale, de l'Innovation et de l'Enseignement Supérieur of the region PACA (Provence-AlpesCôte d'Azur) who are warmly thanked for their support which made these wind tunnel experiments possible.

\section{NOTES}

1. Camber is the depth of curvature of a sail relative to its width (or chord) expressed as a ratio. The narrow Tahiti sail had a 1:7 camber, while the other wider sails varied from 1:10 to 1:11 (Table 1).

2. Tongan, Tahitian, Hawaiian and Marquesas vessels may also be rigged as double canoes, with dedicated bows and sterns.

3. Lewis noted that mat sails make stiffer and better shaped aerofoils. He further wrote that in Ninigo, cloth sails were used for day-to-day fishing and mat sails for racing (Lewis 1999: 29, 30).

4. The Massim sail is shunted by simply hauling the head down to the deck and raising the foot, which becomes the new head. Thus, the sail has a dedicated inside (windward) and outside (leeward) surface.

5. For references on Te Puke today see The Vaka Taumako Project of the Pacific Traditions Society whose principal investigator is Dr Marianne George (http:// www.vaka.org/NSFNotes.html).

6. Leeway is ignored in calculating $C_{R}$ (Marchaj 2003: 154, Fig. 136).

7. Doran (1981: 63) has published sail area and displacement for the Hawaiian spritsail rigged canoe Nalehia and the Carolinian lateen rigged outrigger Mikael. Nalehia has a sail area to displacement ratio only $55 \%$ of that of Mikael.

8. Regarding the central and eastern regions, Kirch (2000: 9) noted that "the extremely wide distribution of the Oceanic lateen sail throughout the island Pacific strongly implies that this was the sail type used on the canoe of early Austronesian speakers when they rapidly dispersed across remote Oceania beginning around 1200 B.C. On the other hand, the restriction of the Oceanic spritsail to Eastern Polynesia shows this to be a later, and independent development". 


\section{REFERENCES}

Anderson, Atholl, 2000. Slow boats from China: Issues in the prehistory of IndoPacific seafaring. In S. O'Connor and P. Veth (eds), East of Wallace's Line: Studies of Past and Present Maritime Cultures of the Indo-Pacific Region. Rotterdam: A. Balkema Press, pp. 13-50.

2001. Towards the sharp end: The form and performance of prehistoric Polynesian voyaging canoes. In C. M. Stevenson, G. Lee and F. J. Morin (eds), Pacific 2000: Proc. of the 5th International Conference on Easter Island and the Pacific. Los Osos: Easter Island Foundation Press, pp. 29-36.

Avis, Chris, Alvaro Montenegro and Andrew Weaver, 2008. Simulating island discovery during the Lapita expansion. In A. Di Piazza and E. Pearthree (eds), Canoes of the Grand Ocean. BAR International Series 1802. Oxford, pp. 121-42.

Beheim, Brett and Adrian Bell, 2011. Inheritance, ecology and the evolution of the canoes of east Oceania. Proceedings of the Royal Society, Biological Sciences 278: 3089-95.

Damon, Frederick, 2000. Notes on Boats for the Eastern Half of the Kula Ring. Unpublished paper presented at Credo, Marseille, May 22.

Di Piazza, Anne, in press. La pirogue monodrome à voile à livarde: 1'outil de peuplement de la Polynésie orientale. In M. Salaün, B. Glowczewski and L. Dousset (eds), Les sciences humaines et sociales dans le Pacifique Sud. Nouveaux terrains, nouvelles approches. Colloque LBSHS 2010. Marseille : Pacific Credo Publications.

Di Piazza, Anne, Philippe Di Piazza and Erik Pearthree, 2007. Sailing virtual canoes across Oceania. Revisiting island accessibility. Journal of Archaeological Science 34 (8): 1219-25.

Dodd, Edward, 1972. Polynesian Seafaring. New York: Dodd, Mead and Company.

Doran, Edwin, 1972. Wa, winta and trimaran. Journal of the Polynesian Society 81: 144-59.

-1981. Wangka: Austronesian Canoe Origins. Texas: A\&M University Press College Station.

Evans, Bradley, 2008 Simulating Polynesian double-hulled canoe voyaging. In A. Di Piazza and E. Pearthree (eds), Canoes of the Grand Ocean. BAR International Series 1802. Oxford, pp. 143-54.

Finney, Ben 1977. Voyaging canoes and the settlement of Polynesia. Science, 196: 1277-85.

2003. Sailing in the Wake of the Ancestors. Reviving Polynesian Voyaging. Honolulu: Bishop Museum Press.

2006. Ocean sailing canoes. In K.R. Howe (ed.), Vaka Moana: Voyages of the Ancestors. Auckland: Bateman, pp. 100-53.

George, Marianne, 1998. The return of Lata: Building an authentic voyaging canoe. Sea History Journal 84: 40-42.

http://www.vaka.org/NSFNotes.html. 
Gillett, Robert, 1993. Traditional Sailing Canoes in Lau - Na Camakau Mai Na Yatu Lau. Suva: Institute of Pacific Studies, University of the South Pacific.

Gladwin, Thomas, 1970. East is a Big Bird: Navigation and Logic on Puluwat Atoll. Cambridge: Harvard University Press.

Greenhill, Simon and Ross Clark, 2011. POLLEX-Online: The Polynesian Lexicon Project Online. Oceanic Linguistics 50 (2): 551-59.

Haddon, Alfred and James Hornell, 1975. Canoes of Oceania. Bernice P. Bishop Museum Special Publication 27, 28 and 29. Honolulu: Bishop Museum Press.

Hiquily, Tara, Jenny Newell, Monique Pullan, Nicole Rode and Arianna Bernucci, 2009. Sailing through history: Conserving and researching a rare Tahitian canoe sail. The British Museum Technical Research Bulletin 3: 1-11.

Horridge, Adrian, 1987. Outrigger Canoes of Bali and Madura, Indonesia. Bernice P. Bishop Museum Special Publication 77. Honolulu: Bishop Museum Press. 2008. Origins and relationships of Pacific canoes and rigs. In A. Di Piazza and E. Pearthree (eds), Canoes of the Grand Ocean. BAR International Series 1802. Oxford, pp. 85-105.

Irwin, Geoffrey, 1992. The Prehistoric Exploration and Colonisation of the Pacific. Cambridge: Cambridge University Press.

-1999. The navigational methods and exploration strategies of the first settlers of the Pacific Ocean. In H. Bader and P. McCurdy (eds), Proceedings of the Waka Moana Symposium 1996: Voyages from the Past to the Future. Auckland: New Zealand National Maritime Museum in partnership with Te Papa National Services and UNESCO, pp. 189-202.

2008. Pacific seascapes, canoe performance, and a review of Lapita voyaging with regard to theories of migration. Asian Perspectives 47 (1): 12-27.

2011. Sailing from Polynesia to the Americas. In T. Jones, A. Storey, E. MatisooSmith and J. Ramirez-Aliaga (eds), Polynesians in America. Pre-Columbian Contact with the Americas. Plymouth: AltaMira Press, pp. 247-62.

Irwin, Geoffrey, Simon Bickler and Philip Quirke, 1990. Voyaging by canoe and computer: Experiments in the settlement of the Pacific. Antiquity 64: 34-50.

Jackson, Peter and Keith Bailey, 1999. Performance prediction of a 'flying proa'. In H. Bader and P. McCurdy (eds), Proceedings of the Waka Moana Symposium 1996: Voyages from the Past to the Future. Auckland: New Zealand National Maritime Museum, in partnership with Te Papa National Services and UNESCO, pp. 307-14.

Kirch, Patrick, 2000. On the Road of the Winds: An Archaeological History of the Pacific Islands before European Contact. Berkeley: University of California Press.

Levison, Michael, Gerard Ward and John Webb, 1973. The Settlement of Polynesia: A Computer Simulation. Minneapolis: University of Minnesota Press.

Lewis, David, 1972. We, the Navigators: The Ancient Art of Landfinding in the Pacific. Honolulu: University of Hawai'i Press. 
Lewis, David, 1999. Voyages. In H. Bader and P. McCurdy (eds), Proceedings of the Waka Moana Symposium 1996: Voyages from the Past to the Future. Auckland: New Zealand National Maritime Museum, in partnership with Te Papa National Services and UNESCO, pp. 12-31.

Malinowski, Bronislaw, 1961. Argonauts of the Western Pacific. New York: Dutton Co, Inc.

Marchaj, Czeslaw, 1964. Sailing Theory and Practice. New York: Dodd, Mead and Co.

1986. Seaworthiness: The Forgotten Factor. London: Adlard Coles Ltd.

-1988. Aero-Hydrodynamics of Sailing. Camden, Maine: International Marine Publishing Co.

2003. Sail Performance, Techniques to Maximize Sail Power. Revised ed., 1st ed. 1996. London: Adlard Coles Nautical.

Munn, Nancy, 1977. The spatiotemporal transformations of Gawa canoes. Journal de la Société des Océanistes 3 (54): 39-53.

Neyret, Jean, 1974. Pirogues océaniennes. Paris : Association des Amis des Musées de la Marine.

Pâris, Edmond [1843]. Essai sur la construction navale des peuples extra-européens ou collection des navires et pirogues construits par les habitants de l'Asie, de la Malaisie, du Grand Océan et de l'Amérique... . Paris: Arthus Bertrand.

Pawley, Andrew and Medina Pawley, 1994. Early Austronesian terms for canoe parts and seafaring. In A.K. Pawley and M.D. Ross (eds), Austronesian Terminologies: Continuity and Change. Pacific Linguistics C-127. Canberra: Australian National University, pp. 329-361.

Rieth, Eric, 1993. Voiliers et Pirogues du Monde au début du XIXe siècle. Essai sur la construction navale des peuples extra-européens de l'amiral Pâris (1843). Paris: Editions du May.

Rogers, Deborah and Paul Ehrlich, 2008. Natural selection and cultural rates of change. Proceedings of the National Academy of Science 105 (9): 3416-20.

Schlichting, Hermann, 1979. Boundary Layer Theory. 7th edition. New York: McGraw-Hill Book Company.

Speiser, Felix, 1996. Ethnology of Vanuatu: An Early Twentieth Century Study. English translation of 1823 German ed. Bathurst: Crawfort House Press.

Thomas, Stephen, 1987. The Last Navigator. New York: Henry Holt and Company. Thomson, Basil, 1908. The Fijians: A Study of the Decay of Custom. London: William Heinemann.

Tilley, Christopher, 2002. The metaphorical transformations of Wala canoes. In V. Buchli (ed.), The Material Culture Reader. Oxford: Berg Publishers, pp. 27-56.

\section{ABSTRACT}

To understand the sailing performance of traditional canoes in Oceania, we replicated ten sail rigs and tested them in a wind tunnel. Measurements of lift and drag forces demonstrate substantial differences in their performance. At low heading angles, from 
about $30^{\circ}$ to $80^{\circ}$ off the wind, three sails (Massim, Ninigo, Santa Cruz) are remarkable for their higher efficiency. Three other sails (Tonga, Hawaii, Tahiti) are remarkable for their lower efficiency from heading angles of about 90 to $130^{\circ}$. In between, four more sails (Arawe, Micronesia, Vanuatu, Marquesas) have roughly similar performance to each other. The ranking of these sails is followed by a description of their distribution with inferences on historical evolution of canoe rigs.

Keywords: Oceania, navigation, sailing canoe performance, wind tunnel experiments, Czeslaw Marchaj, "crab claw" sail

\section{CITATION AND AUTHOR CONTACT DETAILS}

Di Piazza, ${ }^{1}$ Anne; Pearthree, ${ }^{2}$ Erik and Paillé, ${ }^{3}$ François 2014. Wind tunnel measurements of the performance of canoe sails from Oceania. Journal of the Polynesian Society 123(1): 9-28; DOI: http://dx.doi.org/10.15286/jps.123.1.9-28

${ }^{1}$ Corresponding author: Aix-Marseille Université, Centre National de la Recherche Scientifique (CNRS); Ecole des Hautes Etudes en Sciences Sociales (EHESS); Centre de Recherche et de Documentation sur l'Océanie (CREDO), France; email address: anne.dipiazza@pacific-credo.fr

2 Private residential address, France

${ }^{3}$ Ecole Nationale Supérieure de Mécanique et d'Aérotechnique, Chasseneuil-duPoitou, France 